neutralised, at any rate completely, by the serum of immunised animals.

The action of the filtered cultures when given intrarenously in guinea-pigs is seen from the appended table. The results depend naturally upon the strength of the culture, bot with the lysin used in these experiments a dose of 10 cubic centimetres intravenously was usually fatal ; with smaller doses-from one cubic centimetre to eight cubic centimetres-the animals survived. A few hours after the injection the urine passed was a dark reddish-brown, often of the colour of stout, and gave the oxyhæmoglobin spectrum. If the urine was passed shortly after the injection, most commonly no red blood corpuscles were present, but these generally appeared later, and with large doses were found in the urine passed quite early. The hæmoglobin appears to be excreted mostly in the form of oxyhæmoglobin.

When mixed with a small amount of the anti-serum intravenous injections even of large quantities of the lysin produce no hæmoglobinuria, and if the animals receive a subcutaneous injection of the anti-serum the day before the intravenous injection of the lysin no hæmoglobinuria results, showing that the hæmolysis is brought about by a specific lysin and not by a simple chemical or physical action. In this connexion it is interesting to note that in the rabbit-the corpuscles of which are only very slightly affected by the lysis in vitro-large intravenous injections of the lysin produce no hæmoglobinuria.

The fact that a widely distributed organism, which has hitherto been regarded as practically non-pathogenic, is capable of forming products bringing about in susceptible animals such profound blood-changes is of the greatest interest, and although this bacillus may have no causal relation to any pathological condition in man or the lower animals, still the results obtained are suggestive in connexion with the pathology of such diseases as blackwater fever, paroxysmal hæmoglobinuria, and pernicious anæmia. Harrow.

\section{MOVEABLE OR FLOATING KIDNEY A CAUSE OF ACUTE AND CHRONIC PAINFUL DYSPEPSIA,}

\author{
WITH NOTES OF CASES.
}

BY ALEX. MACGREGOR, M.D. ABERD., M.R.C.P. LOND.,

PIISICIAN TO THE NORTH LONDON HOSPITAL FOR CONSUMPTION AND IISEASES OF THE CHEST.

Move_BLLE or floating kidney is by no means rare, yet it is frequently overlooked or apparently not suspected. If in the treatment of cases of chronic painful indigestion a systematic examination of the abdomen be made it not infrequently will be found, especially in women, that the cause of the dyspepsia is not in the stomach itself, but that the interference with the functions of that organ is due to the wanderings of a dislocated kidney. Except in those cases where the dislocation interferes with the functions of the kidney itself no symptom points directly to the nephroytosis. The kidney is not readily thought of as being the cause of an acute attack of jaundice with sickness and severe pain in the epigastrium, yet it has been known to give rise to such symptoms, and the first of the cases hereafter described is an example. Malignant disease of the stomach, too, has been suspected and diagnosed in not a few instances, as in Case 2, where further observation and examination proved a dislocated kidney to be the cause of the grave symptoms. The pain in the region of the pylorus, increased by food, the sickness, emaciation, and the icteric tint of the skin make the diagnosis of malignant disease, and especially in a patient aged about 40 vears, a very natural one. Dr. Herbert Bramwell of Cheltenham recently published a most interesting case which ended fatally. ${ }^{1}$ A post-mortem examination in this case proved the correctness of the diagnosis and added a valuable contribution to our knowledge of the altered condition of parts which gives rise to the symptoms. In Allbutt's System of Medicine ${ }^{2}$ this altered condition of yarts is fully described. There it is stated that bands of jeritoneum produced by the dislocated kidney have been

1 Brit. Med. Jour, Oct. 19th, 1901.

2 Vol. iv, p. 346. found to cause dilatation of the stomach by mechanically obstructing the normal passage of the chyme. "Such bands may pass occasionally from the upper part of the duodenum, but they are more commonly attached to the middle or lower part of the descending portion in the position nearly opposite that at which the bile-duct enters. The drag of the peritoneum on the duodenum is probably the commonest cause of the temporary jaundice which often accompanies the gastric crisis and of the dilatation of the gall-bladder." In the light of this Case 1 is clear and so is Case 3 , which is an exact parallel to the early stage of Dr. Bramwell's case, but fortunately in my patient a short rest in bed and the wearing of a suitable pad and bandage gave complete relief from the symptoms. In the majority of cases the prominent symptoms are indigestion, pain more or less constant, and almost always increased by food, flatulence, and constipation.

The frequency with which moveable kidney is met in women as compared with men is very striking and puts it beyond doubt that there must be a cause at work in women which rarely or never acts in the male. The cases which I have met with seem to me to prove that the most common and most likely cause is tight-lacing plus muscular effort, as, for example, in cycling. One patient whose symptoms suggested malignant disease of the stomach dated the onset of her illness from a 50-mile bicycle ride and another patient of excellent physique began to suffer from the characteristic symptoms immediately after a 12-mile ride over a hilly road against time. In the case of two other female patients falls in the hunting-field were given as the probable cause. One of those two cases is interesting from the fact that for years the patient suffered from indigestion and pain in the right ilio-lumbar region, and by several gynæcologists she had been treated for "something wrong with the ovary and womb," but without benefit. This patient's right kidney lay low down and forward in the lumbar region and could easily be pressed upwards almost to the gall-bladder. The symptoms in this case were always more severe just before, and usually during, the menstrual period. "The catamenial aggravation of the characteristic sensations has been pointed out by Becquet. Lancereaux, Sawyer, and Fourrier." 3 I was able to observo this in Case 1, where with the onset of a menstrual period the kidney became distinctly enlarged and there was a threatening of a return of the gastric crisis with jaundice which accompanied a previous period. In neurotic women the symptoms are often misleading and sensations are felt in parts far removed from the offending kidney. One nervous woman complained of pain in the stomach passing up through the chest to the throat accompanied by distressing "choking sensations and terrible feelings all over the body." Her organs seemed perfectly normal, but the right kidney was freely moveable. Another woman, neurotic and anæmic, complained of occasional loss of voice and choking sensations which she associated with pain in the stomach, and the latter symptom was always increased by food. At first the abdomen was not examined, but as no relief followed the usual medicinal treatment for dyspepsia an examination was made and both kidneys were found to be freely moveable. The thin flaccid abdominal walls made palpation easy, and the kidneys were easily grasped and could be moved over a wide area. An interesting case came under my care while writing these notes. The patient, an unmarried woman, aged 37 years, consulted me on Nov. 20th and gave me a long but clear and intelligent account of years of suffering from indigestion. Two years ago, owing to her inability to take food because of the pain and sickness which it caused, she became terribly emaciated and was sent to a home to undergo the Weir-Mitchell treatment. There she improved immensely, put on weight, and was afterwards able to take a sea voyage. During the voyage, however, the symptoms returned, but they were not so severe. She is now gradually getting back to the condition she was in before undergoing the Weir-Mitchell treatment. She "cannot touch beef or mutton and can take only very small quantities of the simplest food." She was told that she was neurotic (and she knows that she is), but she is "most anxious to be able to eat food like other people." Except for a slight cardiac peculiarity this patient's organs seem perfectly healthy, but the right kidney is dislocated and lies near the upper border of the iliac region and can be pressed up almost to the gall-bladder. Of course, it is impossible 
now to say that the dislocated kidney was the cause of the painful dyspepsia and the resulting emaciation for which she was treated two years ago, but I am more than inclined to think that that is the true explanation of the case. An equally interesting case is that of a young woman who suffered for years from dyspepsia. flatulence, constipation, and pain in the right side of the abdomen, always increased by food. In January, 1900, she was operated upon for appendicitis and was told that the "appendix was very bad." She consulted me 10 months after the operation and said that she still suffered much pain in the right ilio-lumbar region, that the pain was most severe from an hour to an hour and a half after a meal, and that there were obstinate constipation and distressing flatulence. - Aperients and aids to digestion gave only slight and temporary relief and on this account when she consulted me again in January of this zear I examined the abdomen and found the right kidney lying low down in the lumbar region.

Although nephroptosis is most frequently met with in thin women who have had children emaciation is not necessary for its production, nor is it uncommon in unmarried women. Several of my patients had more than an average amount of adipose tissue, and five recently under my care were unmarried.

I have only once met with the condition in a man. His right kidney was enlarged, floating, and, I believe, diseased. He gave a history of having been crushed against a wall by a horse. In less than two years I have seen 12 cases in women, but I shall add short notes of only a few of them.

CASE 1.-A married woman, aged 31 years, the mother of two children, was admitted to the North London Hospital for Consumption under my care on Sept. 23rd, 1901. On Oct. 18th. just before the onset of a menstrual period, she had an attack of acute pain in the right side of the abdomen. I saw her two davs later and then the abdomen was somewhat distended, there was severe pain with tenderness in the epigastrium and to the right of the middle line. The pain was most acute at a point a little above and to the right of the umbilicus. The liver dulness was slightly increased and the rounded end of the distended gall-bladder was palpable, but deep palpation was impossible. On Oct. 28th the acute pain and tenderness were no longer felt and the jaundice was disappearing. Deep palpation was now possible and the right kidney, somewhat enlarged and freely moveable, was found lying well forward in the lumbar region. The patient stated that for six months she had "felt something move or fall in the right side when she turned from one side to the other in bed." At the beginning of the next period there was a return of the same symptoms, but they were much less severe. The kidney again seemed to enlarge somewhat and there was decided tenderness.

CASE 2.-A woman at about the middle period of life, married but having no children, was seen by me in consultation in July, 1900. For some time she had been suffering from pain after food, nausea, and loss of flesh, and there was an icterio tint in the skin-symptoms strongly suggestive of malignant disease of the stomach. Nothing abnormal was to be found in the stomach itself and all the other organs seemed to be perfectly healthy, but the right kidney was dislocated downwards and forwards. She attributed her illness to a trying 50-mile bicycle ride. No malignant disease of the stomach has since developed.

CASE 3.-A woman, aged 32 years, married and the mother of four children, came as an out-patient to the North London Hospital for Ccnsumption on Oct. 8th, 1901. She was very depressed, weak, and emaciated, and there was an icteric int in the skin. Her history was that she had suffered from painful dyspepsia for several years, but the symptoms were much worse since the birth of her last child 10 months ago, and for nearly two months before her visit to the hospital she had been unable to retain a single meal because of the pain which it caused. The emaciation and flaccid condition of the abdominal walls made palpation of the viscera easy. Nothing abnormal was detected in the stomach, but the right kidney was found to be dislocated : it could be easily grasped and moved over a wide area. No medicinal treatment was given, but she was kept in bed for a fortnight, and during that time there was no sickness, and little or no pain. At the end of the fortnight an L-shaped pad kept in place by a suitable bandage was applied and she was no longer confined to bed. There has been no sickness or pain since and the patient eats well and is rapidly putting on flesh.

OASE 4. A married woman, aged 48 years, had suffered more or less for 10 years. She complained of pain in the epigastrium and right hypochondrium and sickness after food, and she stated that the vomiting frequently came on at night. The bowels were alternately relaxed or constipated. Her right kidney was floating.

CASE 5.-A woman, aged 39 years, unmarried, consulted me in November, 1900. She had for years suffered from indigestion, distressing flatulence, constipation, and serere attacks of pain in the neighbourhood of the cardiac erd of the stomach. The pain was frequently accompanied by much retching. The usual remedies gave only slight and temporary relief. Her left kidney was moveable and could easily be grasped and rolled between the fingers in bimanual examination. A pad and bandage gave little or no relief, probably because she was more than fairly stout.

CASE 6.-A woman, aged 39 years, married, and having one child, consulted me in February, 1901. She was distinctly neurotic, stout, and of excellent physique. She complained of vertigo, indigestion, and sudden attacks of pain in the stomach and right lumbar region. The appetite was good, the tongue was clean, and the bowels were relaxed. All the organs seemed healthy. As in the other cases, the remedies gave no relief except as regards the vertigo. The pain was first noticed four months previously after cvcling up some stiff hills. Pain was felt in the abdomen on turning in bed. Owing to the amount of adipose tissue in the abdominal walls palpation was not easy, but the right kidney was made out to be freely moveable. After wearing a pad and bandage the pain was never so severe, but there was still aching.

It is unnecessary to give further details of individual cases. Those which I have given show, I think, that the symptoms and sensations are so characteristic that when in apparently ordinary cases of dyspepsia medicinal treatment fails, moveable or floating kidney ought to be suspected and examined for.

Unfortunately, the treatment by pad and bandage is not always satisfactory, but in none of my cases have I found it necessary to recommend operation. Yet Dr. Bramwell's case shows that nothing short of operation can under certain circumstances save the life of the patient.

The frequency with which nephroptosis is met in women is, as I have already remarked, striking; and no less striking in my experience is the fact that the right kidney is much more frequently dislocated than the left. In my last 12 cases the right kidney was dislocated in eight, the left in three, and both were dislocated in one patient The explanation seems to me to lie in the fact that in muscular effort and serere straining the right kidney gets nipped at its upper end between the muscles of the back behind and by the liver and diaphragm in front and above, and is so pressed out of its normal position.

As regards the method of examination, either for the right or the left kidney, I find it best to stand at the patient right side. The fingers of the left hand are placed in the lumbar region behind and pressed forwards, while the right hand pressing backwards is moved upwards and downwards over the side of the abdomen in front. In this way a dislocated kidney is more or less (according to the condition of the abdominal walls) readily detected and often slips from between the fingers with a distinct jerk.

Queen-street, W.

\section{CHRONIC EPISTAXIS (?VICARIOUS MEN' STRUATION); CAUTERISATION OF THE NOSE, FOLLOWED BY GREAT

$$
\text { GENERAL AND LOCAL }
$$ IMPROVEMENT.}

\section{BY BERNARD E. MYERS, M.D. EDIN, L.R.C.P. LOND.}

THE following case has, I think, certain points of interest. A young woman, aged 23 years, came to see me in June, 1901, on account of anæmia. She looked very ill and had an extremely anxious expression, whilst her cheeks, lips, and conjunctivæ were markedly pale. The patient complained of being in a constant state of hebetude and breathless on the least exertion, of pain and palpitation in the præcordial region and swelling of the ankles in the morning, also of stomach troubles, \&c. She had suffered occasionally from rheumatism. Her family history was as 